\title{
TU/e EmonOWEN

\section{Influence of nitrogen on diamond growth in oxyacetylene combustion chemical vapor deposition}

\section{Citation for published version (APA):}

Okkerse, M., Croon, de, M. H. J. M., Kleijn, C. R., Marin, G. B. M. M., \& van den Akker, H. E. A. (2002). Influence of nitrogen on diamond growth in oxyacetylene combustion chemical vapor deposition. Journal of Applied Physics, 92(7), 4095-4102. https://doi.org/10.1063/1.1502925

DOI:

$10.1063 / 1.1502925$

Document status and date:

Published: 01/01/2002

\section{Document Version:}

Publisher's PDF, also known as Version of Record (includes final page, issue and volume numbers)

\section{Please check the document version of this publication:}

- A submitted manuscript is the version of the article upon submission and before peer-review. There can be important differences between the submitted version and the official published version of record. People interested in the research are advised to contact the author for the final version of the publication, or visit the $\mathrm{DOI}$ to the publisher's website.

- The final author version and the galley proof are versions of the publication after peer review.

- The final published version features the final layout of the paper including the volume, issue and page numbers.

Link to publication

\section{General rights}

Copyright and moral rights for the publications made accessible in the public portal are retained by the authors and/or other copyright owners and it is a condition of accessing publications that users recognise and abide by the legal requirements associated with these rights.

- Users may download and print one copy of any publication from the public portal for the purpose of private study or research.

- You may not further distribute the material or use it for any profit-making activity or commercial gain

- You may freely distribute the URL identifying the publication in the public portal.

If the publication is distributed under the terms of Article 25fa of the Dutch Copyright Act, indicated by the "Taverne" license above, please follow below link for the End User Agreement:

www.tue.nl/taverne

Take down policy

If you believe that this document breaches copyright please contact us at:

openaccess@tue.nl

providing details and we will investigate your claim. 


\title{
Influence of nitrogen on diamond growth in oxyacetylene combustion chemical vapor deposition
}

\author{
M. Okkerse \\ Laboratorium voor Chemische Procestechnologie, Eindhoven University of Technology, P.O. Box 513, \\ 5600 MB Eindhoven, and Kramers Laboratorium voor Fysische Technologie, Delft University of Technology, \\ Prins Bernhardlaan 6, 2628 BW Delft, The Netherlands \\ M. H. J. M. de Croon \\ Laboratorium voor Chemische Procestechnologie, Eindhoven University of Technology, P.O. Box 513, \\ 5600 MB Eindhoven, The Netherlands \\ C. R. Kleijna) \\ Kramers Laboratorium vor Fysische Technologie, Delft University of Technology, Prins Bernhardlaan 6, \\ 2628 BW Delft, The Netherlands \\ G. B. Marin \\ Laboratorium voor Petrochemische Techniek, University of Ghent, Krijgslaan 128, B-9000 Gent, Belgium \\ H. E. A. van den Akker \\ Kramers Laboratorium vor Fysische Technologie, Delft University of Technology, Prins Bernhardlaan 6, \\ 2628 BW Delft, The Netherlands
}

(Received 30 May 2002; accepted for publication 1 July 2002)

\begin{abstract}
Addition of di-nitrogen to the feed gas has been shown to greatly influence growth rates and morphology of the deposited layer in various diamond chemical vapor deposition (CVD) techniques. In this article, several hypotheses for these phenomena, as presented in literature, are tested for the case of diamond combustion CVD with the aid of an atmospheric pressure oxyacetylene flame. For this purpose, one-dimensional and two-dimensional simulations are performed of the hydrodynamics, the combustion and deposition chemistry, and the nitrogen chemistry. Based on the simulation results, several proposed hypotheses can be ruled out as possible explanations for the observed phenomena. It is concluded, that the most likely hypotheses are: (i) the presence of nitrogen atoms in the diamond lattice, enhancing diamond growth by acting on the electron structure of surface dimer bonds, and (ii) selective adsorption of nitrogen-containing species on the surface, selectively increasing growth in the (100) direction. It is found that possible gas phase candidates for affecting diamond growth are $\mathrm{NH}, \mathrm{NH}_{2}, \mathrm{NH}_{3}, \mathrm{CN}, \mathrm{HCN}, \mathrm{H}_{2} \mathrm{CN}$, and NCO. (C) 2002 American Institute of Physics. [DOI: 10.1063/1.1502925]
\end{abstract}

\section{INTRODUCTION}

The unique properties of diamond ${ }^{1}$ make it an attractive candidate for a variety of industrial applications. In particular single-crystalline diamond is a promising material for, among others, electronic and optical applications. ${ }^{2}$ The largest barrier for exploitation is that centimeter size, single crystal diamond films are not readily available on the market.

With oxyacetylene combustion chemical vapor deposition (CVD), high-quality single-crystal layers can be grown at high growth rates and low cost. ${ }^{3-5}$ In this technique, a laminar, atmospheric pressure oxyacetylene flame (in fact an ordinary welding torch), is pointed toward a substrate (see Fig. 1). The nozzle-to-substrate distance $L$ is on the order of $1 \mathrm{~cm}$, and the flame-tip-to-substrate distance $d$ and the nozzle diameter $D$ are on the order of $1 \mathrm{~mm}$. The flame is fed by a slightly supersaturated mixture of acetylene and oxygen. As opposed to classical thermal CVD processes, in which the gas and the substrate are heated through external heat

a) Author to whom correspondence should be addressed; electronic mail: crkleijn@klft.tn.tudelft.nl sources, the energy required to drive the chemical reactions in combustion CVD is provided by the exothermic combustion reactions themselves. The premixed feed gas at room temperature flows through the burner nozzle to combust to (mainly) $\mathrm{CO}$ at the flame front. This flame front has a conical shape, as can be seen in Fig. 1. In the hot (>3300 K) flame front, reactive species such as the $\mathrm{CH}_{3}$ radical are created, as well as etching species such as atomic oxygen and hydrogen. At the substrate surface, which is cooled to approximately $1400 \mathrm{~K}$, a delicate balance between diamond growth and etching leads to the deposition of high-quality single-crystal diamond. As yet, the area of growth obtained by oxyacetylene combustion CVD is limited to about $20 \mathrm{~mm}^{2}$. To be able to produce centimeter size diamond layers, the process has to be scaled up.

For successful scale-up, a thorough understanding is needed of the hydrodynamics and the combustion chemistry in the flame, in interaction with each-other and with the substrate surface. As for classical CVD processes,${ }^{6-10}$ such an understanding may gain from simulation models combining hydrodynamics and chemistry. Such a study for diamond 


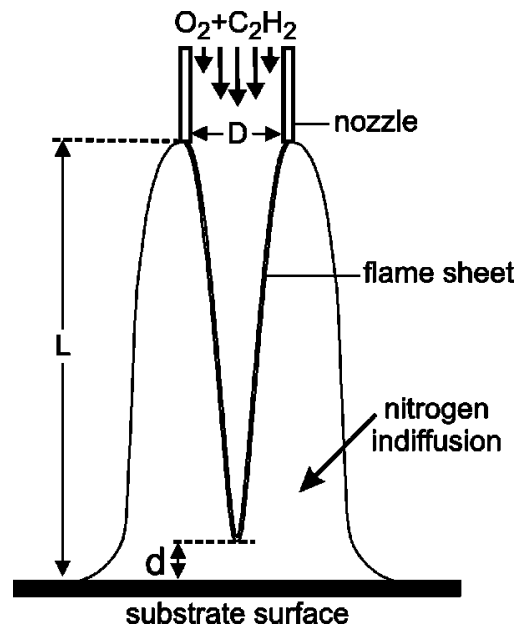

FIG. 1. Schematic representation of the experimental and simulated flame setup.

CVD from flat methane/air flames, using simplified combustion chemistry, was presented by Di Muzio and co-workers. ${ }^{11}$ Meeks and co-workers ${ }^{12}$ presented a model for diamond CVD from a one-dimensional oxyacetylene flame. For diamond CVD from two-dimensional, conical oxyacetylene flames, we have previously presented detailed models for the homogeneous combustion chemistry and the heterogeneous diamond growth chemistry in Ref. 13, which we have subsequently combined with a two-dimensional hydrodynamic model for laminar oxyacetylene flames. ${ }^{14}$ These models were validated against experimental data ${ }^{15-18}$ on growth rates and concentration profiles of gas phase intermediates $\mathrm{C}, \mathrm{CH}$, and $\mathrm{H}$, as a function of flame-tip-to-substrate distance and substrate temperature. Our combined chemistry and hydrodynamic models were found to provide valuable insights in various important underlying mechanisms of oxyacetylene combustion CVD of diamond. The models gave correct predictions of flame lengths and shapes, as well as qualitatively and semiquantitatively correct predictions of the flame temperature, gas phase concentration profiles, and diamond growth rates.

An important effect, which could not be explained on the basis of the hydrodynamics and combustion chemistry alone, is the experimental observation that a $4-5 \mathrm{~mm}$ diam central region of good quality and uniform diamond is bordered by an annular region of enhanced growth and decreased quality, displaying amorphous features. ${ }^{18}$ The presence of this annulus strongly limits the area size of good quality diamond that can be grown, and it also seriously hinders scale-up strategies such as the use of multiple flame nozzles or scanning the substrate surface with a single flame. The presence of this annulus has been ascribed to in-diffusion of nitrogen from the ambient air into the flame ${ }^{18}$ (see Fig. 1).

Indeed, in various diamond CVD techniques, the addition of small amounts of nitrogen to the feed gas has been found to lead to large changes in growth rate and surface morphology. In microwave plasma reactors, fed with predominantly hydrogen and up to $2 \%$ methane, addition of nitrogen results in a transition from nanocrystalline growth or growth in the (111) or (110) direction, to growth in the
(100) direction. ${ }^{19-23}$ Optimal diamond quality is found for additions between 100 and 500 ppm nitrogen. ${ }^{19,22}$ Further increasing the addition of di-nitrogen leads to a decrease of the diamond quality: cauliflower structures were observed under the microscope. Roughly the same trends are observed in hot filament reactors, ${ }^{24-27}$ where the diamond quality increases up to nitrogen additions of $100 \mathrm{ppm}$, and the growth rate increases with the nitrogen concentration at low filament temperatures, while it decreases at high filament temperatures. ${ }^{24}$

The feed gas composition in oxyacetylene combustion CVD largely differs from that in microwave and hot filament reactors. It roughly consists of 50\% acetylene and 50\% oxygen. In practice, the acetylene feed contains traces of dinitrogen and oxygen. The effect of addition of different nitrogen-containing species to the feed was studied by Atakan and co-workers. ${ }^{28}$ Schermer, de Theije, Stolk and co-workers ${ }^{29-31}$ studied the influence of di-nitrogen on the growth under oxyacetylene flame deposition conditions, for di-nitrogen concentrations in the feed between 600 and $32000 \mathrm{ppm}$. Since there was some di-nitrogen present in the acetylene bottle, the minimum di-nitrogen content in the feed was $\sim 600 \mathrm{ppm}$. Therefore, a possible increase in diamond quality at lower concentrations could not be observed, but the subsequent decrease at higher concentrations was. The growth rate was found to increase linearly with di-nitrogen up to about $5000 \mathrm{ppm}$, above which it leveled off, and eventually decreased. An increasing amount of nitrogen was found in the diamond lattice, ${ }^{19,29,32}$ and cauliflower structures were observed above the same boundary of $5000 \mathrm{ppm}$.

Various explanations have been proposed for the observed phenomena: (i) Depletion of the gaseous diamond precursors (which are carbon containing species that are relatively reactive), owing to formation of $\mathrm{CN}^{.24,33-37}$ This hypothesis is supported by an observed decreased $\mathrm{C}_{2}$ concentration in microwave plasma CVD when nitrogen is added. (ii) A decrease in the atomic hydrogen concentration in the gas phase, which leads to changes in the gas-phase chemistry. ${ }^{26}$ (iii) Formation of $\mathrm{CN}$ in the gas-phase, abstracting hydrogen from the surface, so called etching, in a similar way as is known from atomic hydrogen. ${ }^{22,23,33,38}$ (iv) The presence of nitrogen atoms in the diamond lattice, enhancing diamond growth by acting on the electron structure of surface dimer bonds. ${ }^{25}$ (v) Selective adsorption of nitrogencontaining species like $\mathrm{NH}_{x}$ or $\mathrm{CNH}_{x}$ on the surface, selectively increasing growth in the (100) direction. ${ }^{39}$ It should be noted that the first two hypotheses require a significant influence of added di-nitrogen on the hydrocarbon combustion process. For the third hypothesis to hold, gas-phase $\mathrm{CN}$ concentrations should be of the same order of magnitude as the concentrations of other (known) etching species, such as atomic $\mathrm{O}$ and $\mathrm{H}$. The last two hypotheses, however, may hold even for very low concentrations of nitrogen containing species.

In the present article, these different hypotheses are evaluated for the case of diamond deposition from an oxyacetylene flame, with the aid of one- and two-dimensional simulations of the flame hydrodynamics and chemistry, including nitrogen chemistry. To this end, we study the influ- 
ence on di-nitrogen on the combustion process and we calculate concentration distributions of nitrogen-containing species in the gas phase and near the growth surface.

\section{SIMULATION MODELS}

\section{A. Reactor geometry}

The studied axisymmetric reactor configuration is illustrated in Fig. 1. A feed gas mixture of oxygen and acetylene (with a trace of di-nitrogen) at room temperature and atmospheric pressure enters the domain through a cold, cylindrical nozzle tube with a diameter $D=1.4 \mathrm{~mm}$, at an average velocity of $58 \mathrm{~m} / \mathrm{s}$. The nozzle-to-substrate distance is $L$ $=8 \mathrm{~mm}$. In order for diamond growth to take place, the flame should be slightly supersaturated, i.e., there should be a small excess of acetylene in the feed, compared to a neutral flame. The excess acetylene $S_{\mathrm{ac}}$ is defined as the fraction of acetylene that is fed in excess to that of a neutral flame.

From simple theoretical considerations, assuming that all acetylene combusts to $\mathrm{CO}$, a neutral flame is expected to occur at a feed gas composition of 50\%:50\% $=1.0$ molar ratio of acetylene and oxygen. In practice, however, the combustion process is more complex and not all acetylene is combusted into CO. As a result, neutral flames are obtained experimentally at a slightly smaller molar ratio of acetylene and oxygen, viz. 47.5:52.5 $=0.90 .{ }^{16}$ Experimentally, good diamond growth is obtained at an the excess acetylene of approximately $S_{\text {ac }}=5 \%$, corresponding to a feed gas composition of $48.72: 51.28=0.95$ molar ratio of acetylene and oxygen. This value has been used in our simulations. The flame-tip-to-substrate distance is $d \approx 0.6 \mathrm{~mm}$. The flame impinges perpendicularly on to a horizontal substrate with a temperature of $1400 \mathrm{~K}$, on which diamond deposition takes place.

\section{B. Hydrodynamic model}

In formulating the hydrodynamic simulation model, the following assumption are made: (i) the process is stationary in time; (ii) the flame is axisymmetric; and (iii) the absorption or emission of radiation energy can be neglected. ${ }^{12}$

The composition of the $N$-component gas mixture is described in terms of the dimensionless mass fractions $\omega_{i}$ ( $i$ $=1 \ldots N)$ of its constituents. The diffusion of gas species is expressed through their diffusive mass fluxes $\mathbf{j}_{i}$ with respect to the mass averaged velocity $\mathbf{v} .^{40}$ The transport of mass, momentum and heat is described by the continuity equation, the Navier-Stokes equations and the transport equation for thermal energy ${ }^{40,41}$

$$
\begin{aligned}
\frac{\partial \rho}{\partial t}= & -\nabla \cdot(\rho \mathbf{v}), \\
\frac{\partial(\rho \boldsymbol{v})}{\partial t}= & -\nabla \cdot(\rho \mathbf{v v}) \\
& +\nabla \cdot\left[\mu\left(\nabla \mathbf{v}+(\nabla \mathbf{v})^{\dagger}\right)-\frac{2}{3} \mu(\nabla \cdot \mathbf{v}) \mathbf{I}\right]-\nabla P+\rho \mathbf{g},
\end{aligned}
$$

$$
\begin{aligned}
c_{p} \frac{\partial(\rho T)}{\partial t}= & -c_{p} \nabla \cdot(\rho \mathbf{v} T)+\nabla \cdot(\lambda \nabla T) \\
& -\sum_{i=1}^{N} \sum_{k=1}^{K} H_{i} v_{i k} R_{k}-\sum_{i=1}^{N} \mathbf{j}_{i} \cdot \nabla \frac{H_{i}}{M_{i}} .
\end{aligned}
$$

Here, $P, T$, and $\mathbf{v}$ are the pressure, temperature, and mass averaged velocity of the gas mixture; $\rho, \mu, c_{p}$, and $\lambda$ are its density, viscosity, specific heat per unit mass, and thermal conductivity; $t$ is the time; $R$ the gas constant; and $\mathbf{g}$ is the gravitational acceleration. Gas species $i$ has a mole fraction $f_{i}$, a molar mass $M_{i}$, and a molar enthalpy $H_{i}$. There are $K$ reversible gas phase reactions, with net molar reaction rates $R_{k}$ and net stoichiometric coefficients $v_{i k}$. In the thermal energy equation, Eq. (3), the Dufour effect has been neglected. ${ }^{41}$

The transport equation for the $i$ th gas species is given by

$$
\frac{\partial\left(\rho \omega_{i}\right)}{\partial t}=-\nabla \cdot\left(\rho \mathbf{v} \omega_{i}\right)-\nabla \cdot \mathbf{j}_{i}+M_{i} \sum_{k=1}^{K} \nu_{i k} R_{k} .
$$

Since the mass fraction must sum up to unity, this equation is solved for all species except one. In the rigorous kinetic theory of $N$-component gas mixtures ${ }^{42}$ it is shown that there can be various driving forces for diffusion. In laminar flames, the relevant driving forces are the concentration and temperature gradients, and the total diffusion flux $\mathbf{j}_{i}$ is a summation of a diffusion flux $\mathbf{j}_{i}^{C}$ due to concentration gradients and a diffusion flux $\mathbf{j}_{i}^{T}$ due to temperature gradients

$$
\mathbf{j}_{i}=\mathbf{j}_{i}^{C}+\mathbf{j}_{i}^{T} .
$$

Multicomponent concentration gradient driven diffusion is modeled through the Wilke approximation, and thermodiffusion through the Clark-Jones approximation. ${ }^{41}$

The transport equations are supplemented with the usual boundary conditions in the inlet (i.e., fixed temperature equal to room temperature, fixed species mole fractions as described above, and a fixed velocity profile). On the walls of the burner tube, we impose a fixed temperature, equal to room temperature. On the impingement surface, the temperature is fixed at $1400^{\circ} \mathrm{C}$. On the other boundaries of the domain, a fixed pressure is imposed, allowing for gas to leave or enter the domain. Gas entering the domain at these boundaries is assumed to be air at room temperature. The thermochemical properties of each of the gas species in the gas mixture, as a function of temperature, have been taken from the CHEMKIN thermodynamic database. ${ }^{43}$ The transport properties of the individual gas species were calculated from kinetic theory, ${ }^{41,42,44}$ assuming the Lennard-Jones (6-12) intermolecular potential energy function. The Lennard-Jones parameters were taken from the CHEMKIN TRANSPORT DATABASE. ${ }^{44}$ The mixture viscosity and thermal conductivity are calculated from semiempirical mixture rules. ${ }^{45}$

\section{Hydrocarbon combustion chemistry model}

The gas-phase kinetic mechanism used in our study is based on the hydrocarbon combustion mechanism by Miller and co-workers, ${ }^{46}$ which has been previously applied to acetylene-oxygen flames by Meeks and co-workers. ${ }^{12}$ 


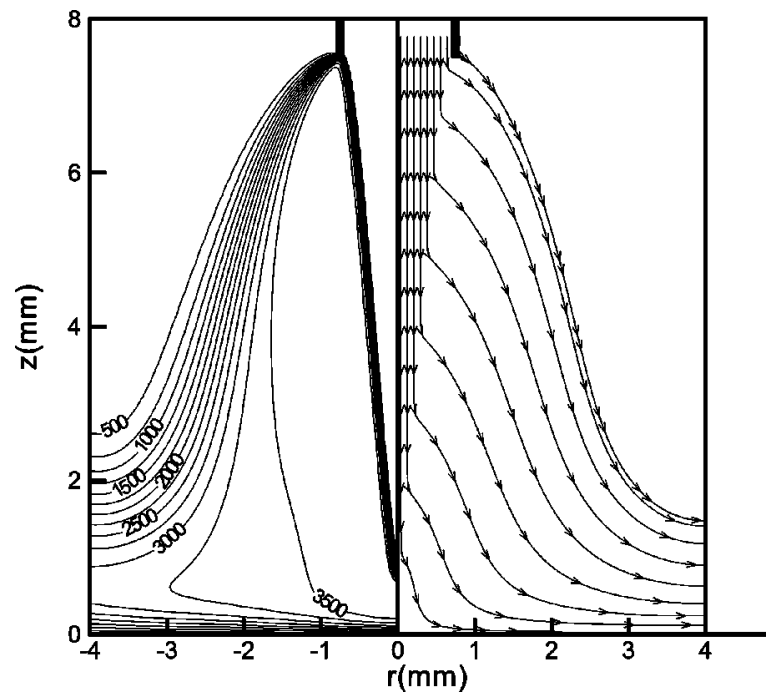

FIG. 2. Calculated isotherms (left, in K) and streamlines (right) in the impinging oxyacetylene flame reactor configuration.

Through sensitivity analyses in one-dimensional flame simulations, we have reduced the original 48 species, 219 reactions mechanism to a 27 species, and 119 reactions mechanism. ${ }^{13}$ Based on quantum-mechanical calculations by Skokov and co-workers, ${ }^{47-49}$ we developed a surface reaction mechanism consisting of 67 elementary reactions between 41 adsorbed species, based on the so called mean field approximation. ${ }^{13}$ It contains $\mathrm{CH}_{3}$ and $\mathrm{C}_{2} \mathrm{H}_{2}$ as gaseous growth precursors, and atomic hydrogen and oxygen as etching species. Earlier, ${ }^{13,14}$ these two chemistry models were combined with one-dimensional (1D) and two-dimensional (2D) hydrodynamic model.

Figure 2 shows calculated isotherms and streamlines as calculated by the 2D model. As shown in Ref. 14, with the 2D model axial and radial hydrocarbon gas phase concentration profiles, radial growth rate profiles, and trends in film growth rates as a function of, e.g., surface temperature and flame-tip-to-substrate distance can be predicted in good qualitative agreement with experimental data. Without inclusion of nitrogen chemistry, however, the model is not capable of predicting the influence of nitrogen in the flame on diamond growth rate and quality.

Therefore, in the present article, the diamond-CVD chemistry model has been extended with a model for the gas phase nitrogen chemistry, and combined with either a 1D flat flame model, ${ }^{50}$ or a full $2 \mathrm{D}$ axisymmetric model for the flame hydrodynamics. ${ }^{41}$

\section{Nitrogen chemistry model}

Nitrogen in the flame originates from two different sources: First, the acetylene that is fed into the welding torch in practice contains a trace of approximately $1500 \mathrm{ppm}$ dinitrogen. Secondly, di-nitrogen diffuses inward into the flame from the surrounding air. The stream trace in Fig. 2 that starts from the edge of the burner is the dividing line between the ambient air and the flame region that consists of hot combustion products. We expect the occurrence of nitrogen-containing radical species originating from ambient-air nitrogen around this line. This area will be called the outer flame region. The stream trace will be called the outer flame streamline.

As will be seen below, the nitrogen from the two sources reacts through different routes. In general, three routes can be distinguished through which di-nitrogen is decomposed, which can briefly be summarized as

(1) The Zeldovich mechanism

$$
\begin{aligned}
& \mathrm{N}_{2}+\mathrm{O} \rightarrow \mathrm{NO}+\mathrm{N}, \\
& \mathrm{N}+\mathrm{O}_{2} \rightarrow \mathrm{NO}+\mathrm{O}, \\
& \mathrm{N}+\mathrm{OH} \rightarrow \mathrm{NO}+\mathrm{H} .
\end{aligned}
$$

(2) $\mathrm{N}_{2} \mathrm{O}$ intermediate mechanism

$$
\begin{aligned}
& \mathrm{N}_{2}+\mathrm{O}(+M) \rightarrow \mathrm{N}_{2} \mathrm{O}(+M), \\
& \mathrm{H}+\mathrm{N}_{2} \mathrm{O} \rightarrow \mathrm{NO}+\mathrm{NH}, \\
& \mathrm{O}+\mathrm{N}_{2} \mathrm{O} \rightarrow \mathrm{NO}+\mathrm{NO}, \\
& \mathrm{H}+\mathrm{N}_{2} \mathrm{O} \rightarrow \mathrm{N}_{2}+\mathrm{OH}, \\
& \mathrm{O}+\mathrm{N}_{2} \mathrm{O} \rightarrow \mathrm{N}_{2}+\mathrm{O}_{2} .
\end{aligned}
$$

(3) The Fenimore mechanism

$$
\mathrm{N}_{2}+\mathrm{CH} \rightarrow \mathrm{HCN}+\mathrm{N}
$$

(for a further and more detailed description of all three routes, see Ref. 51). From these reactions it follows that either $\mathrm{O}$ or $\mathrm{CH}$ must be present in order to decompose dinitrogen.

In the present study we use a gas phase reaction mechanism which, in addition to the combustion reactions described in Sec. III C, consists of a detailed nitrogen chemistry mechanism taken from Kilpinen et al. ${ }^{52}$ In addition to the above reactions (6)-(14), it includes a large number of elementary gas phase reactions, involving the nitrogencontaining species $\mathrm{N}, \mathrm{N}_{2}, \mathrm{NH}, \mathrm{NH}_{2}, \mathrm{NH}_{3}, \mathrm{~N}_{2} \mathrm{H}, \mathrm{NO}, \mathrm{NO}_{2}$, $\mathrm{N}_{2} \mathrm{O}, \mathrm{HNO}, \mathrm{CN}, \mathrm{HCN}, \mathrm{NCO}, \mathrm{HOCN}, \mathrm{HNCO}, \mathrm{HCNO}$, and $\mathrm{H}_{2} \mathrm{CN}$.

\section{RESULTS}

\section{A. 1D flat flame simulations}

As a first study on the decomposition of di-nitrogen present in the feed gas, a flat flame is simulated with the aid of a one-dimensional premixed flat flame model, ${ }^{53}$ fully coupled with the combustion and nitrogen chemistry models described above. $0-8000 \mathrm{ppm}$ di-nitrogen is added to the reactor feed. The gas mixture is fed to the flat flame reactor with a specified flow rate, and is made to ignite directly behind the inlet.

Figure 3 shows the concentration profile of the most abundant reaction products of di-nitrogen, for a feed concentration di-nitrogen of $1000 \mathrm{ppm}$. Di-nitrogen is decomposed at and directly behind the flame front, mainly via the Fenimore mechanism, and $\mathrm{HCN}$ is the first species that is produced. The atomic nitrogen formed via the first step of the Zeldovich mechanism and via the Fenimore mechanism partly reacts further to form $\mathrm{HCN}$ and $\mathrm{NO}$ as the most important products. A detailed quantitative analysis of all reac- 


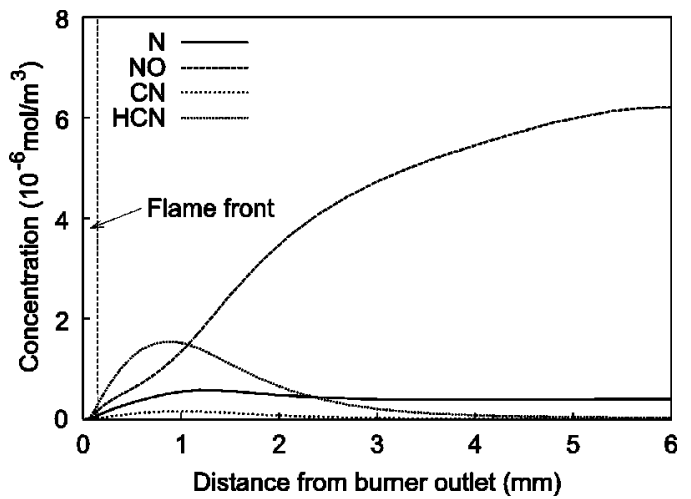

FIG. 3. Concentration profiles of the most abundant nitrogen-containing species, as calculated with a $1 \mathrm{D}$ premixed flame model for a di-nitrogen feed concentration of $1000 \mathrm{ppm}$.

tion routes showed that, overall, di-nitrogen is decomposed in a ratio of approximately 1:0.5:0.2 through the Fenimore : Zeldovich : $\mathrm{N}_{2} \mathrm{O}$ mechanisms. The simulations predict that, 6 $\mathrm{mm}$ downstream from the flame front, less than $1 \%$ of the added di-nitrogen is converted. $\mathrm{HCN}$ is the most important nitrogen-containing product directly behind the flame front. However, further downstream, $97 \%$ of the formed $\mathrm{HCN}$ is converted to $\mathrm{NO}$ with the aid of $\mathrm{O}, \mathrm{OH}$, and $\mathrm{H}$. Here, $\mathrm{NO}$ is by far the most abundant nitrogen-containing species. Although there are indications that NO might play a role in oxyacetylene flame CVD of diamond at low pressures, ${ }^{54}$ it appears to be unimportant under atmospheric pressure flame conditions. ${ }^{55}$

Due to its low conversion, the addition of di-nitrogen was found to have hardly any effect on the concentration of the non-nitrogen-containing species. The first two hypotheses given in Sec. I, viz. a significant influence of di-nitrogen on the gas-phase concentrations of either a diamond precursor or atomic hydrogen, were therefore not substantiated here. The third hypothesis, an etching role of $\mathrm{CN}$ on the surface comparable to that of $\mathrm{H}$, could not be supported either. The maximum $\mathrm{CN}$ concentration in the flame is a factor $10^{5}$ lower than the maximum concentration of atomic hydrogen. In fact, since the maximum concentrations of all nitrogen-containing gas-phase species are very low, it is unlikely that any nitrogen-containing species influences diamond growth via a direct etching effect.

Thus, the most likely hypotheses are (iv) and (v), i.e., that nitrogen is included in the diamond lattice, or adsorbs on the surface, and influences diamond growth in this way. It has been found that the amount of nitrogen included in the lattice is very low, and increases with the di-nitrogen concentration in the feed. ${ }^{19,29,32}$ This might be in support of hypothesis (iv). Also, there appears to be a linear relation between the di-nitrogen concentration in the feed gas and the diamond growth rate. ${ }^{29}$ Our simulations show, that the concentrations of all nitrogen-containing species included in the mechanism vary linearly with the di-nitrogen content in the feed, up to the higher level of $8000 \mathrm{ppm}$. Although their concentrations are low, they could well be responsible for the observed very small amounts of nitrogen in the lattice. Therefore, each of
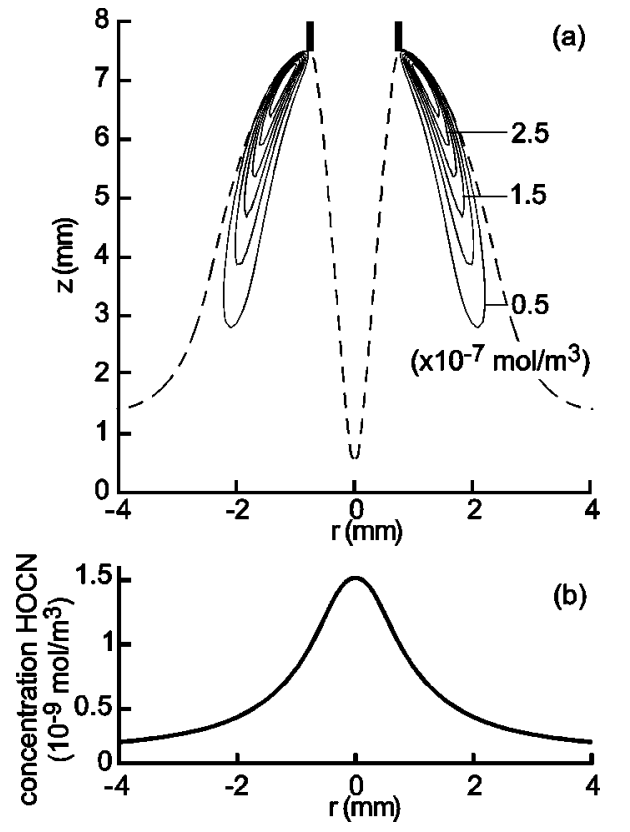

FIG. 4. 2D simulations of HOCN concentrations, for a di-nitrogen feed concentration of $1000 \mathrm{ppm}$. (a) 2D gas-phase iso-concentration contours. Dotted lines indicate the location of the flame front and of the outer flame streamline. (b) Radial distribution of the gas-phase concentration, at a distance of $2 \mu \mathrm{m}$ from the substrate surface. Qualitatively similarly shaped concentration distributions have been found for HNCO and HCNO.

the simulated nitrogen-containing species could in principle be the precursor of the nitrogen in the diamond lattice.

\section{B. Two-dimensional flame simulations}

In order to further discriminate between the various nitrogen-containing species and their impact on film growth, and to study the effect of nitrogen in-diffusion from the ambient air, flame simulations have been performed combining the full combustion and nitrogen chemistry models described above with the 2D hydrodynamic flame model described above and in Ref. 14. This provides information on the radial concentration profiles of the various species just above the substrate surface, which may be compared to experimental growth rate profiles.

For the numerical solution of the model equations, we use our CVD simulation code CVDMODEL. ${ }^{56,57}$ The equations are discretized with the aid of the finite volume method on a 2D cylindrical grid of $N_{r} \times N_{z}=61 \times 149$ grid cells. A cell at the flame front typically has a radial dimension of $17 \mu \mathrm{m}$ and the sharp temperature rise in the flame front is spanned by at least five grid cells. In axial direction, the typical grid size is $60 \mu \mathrm{m}$, which is refined near the substrate to $4 \mu \mathrm{m}$. Grid independence was checked by increasing the number of grid points with $50 \%$ in both directions. The di-nitrogen concentration in the feed was set to $1000 \mathrm{ppm}$, the flame-tip-tosubstrate distance was $d=0.6 \mathrm{~mm}$. Since the nitrogen chemistry does not influence the combustion chemistry significantly, as shown above, it has been calculated separately from the combustion chemistry, in a "postprocessing step." Nitrogen containing species are assumed not to react at the diamond surface. 

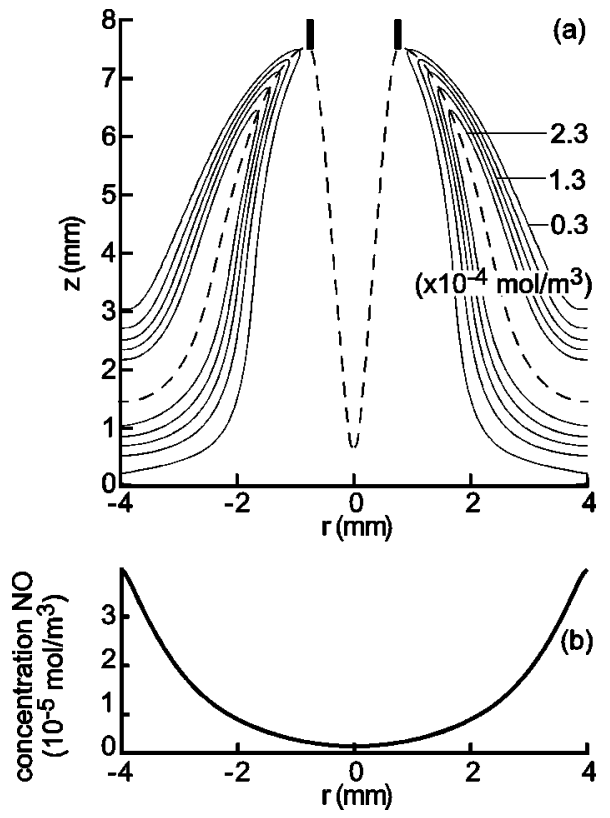

FIG. 5. 2D simulations of NO concentrations, for a di-nitrogen feed concentration of $1000 \mathrm{ppm}$. (a) 2D gas-phase iso-concentration contours. Dotted lines indicate the location of the flame front and of the outer flame streamline. (b) Radial distribution of the gas-phase concentration, at a distance of $2 \mu \mathrm{m}$ from the substrate surface. Qualitatively similarly shaped concentration distributions have been found for $\mathrm{HNO}, \mathrm{N}_{2} \mathrm{O}, \mathrm{NO}_{2}, \mathrm{~N}_{2} \mathrm{H}$, and $\mathrm{N}_{2}$.

Figures 4(a)-6(a) show 2D iso-concentration contours of three selected nitrogen-containing reaction products in the reactor. For reference, the location of the flame front and of the outer flame streamline are also shown in these figures (dotted lines). Figures 4(b)-6(b) show radial concentration profiles of the same species, directly above the diamond surface, i.e., at $z \downarrow 0$.

Figure 4(a) shows the simulated concentration profiles of one of the reaction products of di-nitrogen, viz. HOCN. It shows some typical features found for all di-nitrogen reactions products: High concentrations are found in the outerflame region, owing to reaction of di-nitrogen from the ambient air with hot combustion products. Di-nitrogen reaction products are also created at the flame front, were di-nitrogen from the feed reacts. This creates a local concentration maximum around the flame front. However, compared to the amount of nitrogen diffusing into the flame from the ambient air, the amount of nitrogen in the feed is low. Consequently, the concentration maximum around the flame front is much lower than the concentrations in the outer flame region, and this local maximum is not visible on the scale of this figure. The same was found to hold for all other simulated nitrogencontaining species. For most of them, concentrations in the outer flame region were more than 100 times higher than those at the flame front. This is in agreement with measurements with the aid of laser induced fluorescence, ${ }^{55,18}$ which show that $\mathrm{CN}$ concentrations at the flame front are at least ten times smaller than those in the outer flame region.

Since the concentrations of nitrogen-containing species in the outer flame region, originating from ambient air dinitrogen diffusing into the flame, are so much larger than the concentrations near the flame front, which originate from
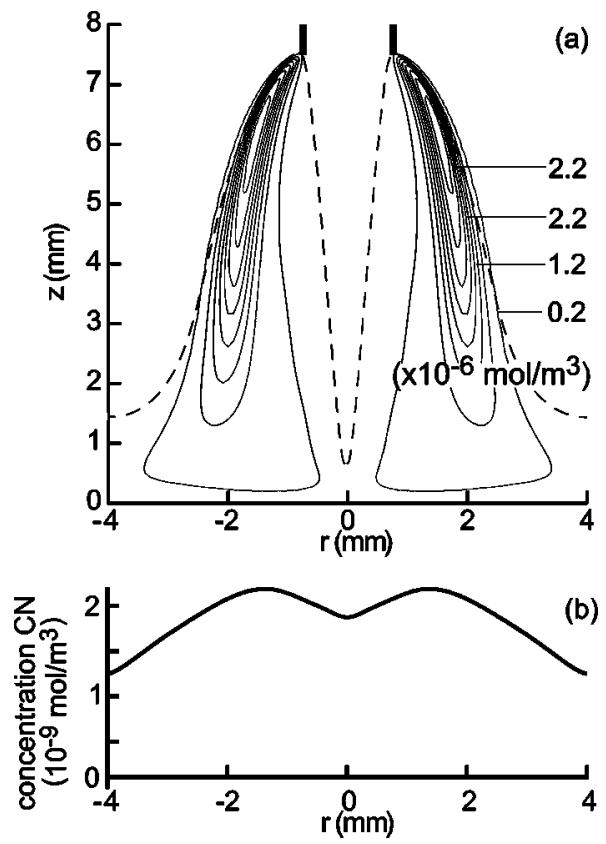

FIG. 6. 2D simulations of $\mathrm{CN}$ concentrations, for a di-nitrogen feed concentration of 1000 ppm. (a) 2D gas-phase iso-concentration contours. Dotted lines indicate the location of the flame front and of the outer flame streamline. (b) Radial distribution of the gas-phase concentration, at a distance of $2 \mu \mathrm{m}$ from the substrate surface. Qualitatively similarly shaped concentration distributions have been found for $\mathrm{NH}, \mathrm{NH}_{2}, \mathrm{NH}_{3}, \mathrm{HCN}, \mathrm{H}_{2} \mathrm{CN}$, and NCO.

di-nitrogen in the feed, the question arises which of these two di-nitrogen sources contributes most to the presence of nitrogen near the center of the substrate surface. Figure 7 shows that $\mathrm{N}_{2}$ diffusing into the flame from the ambient air does not penetrate all the way to the center of the substrate. Even when the flame-tip-to-substrate distance is increased to $d=2.6 \mathrm{~mm}$, this does not occur. Consequently, the dinitrogen that is present near $r=0$ predominantly originates from the feed gas. When di-nitrogen from the feed gas is omitted, the concentration of $\mathrm{N}_{2}$, and of all nitrogencontaining reaction products, near the substrate center drops by at least a factor 10 . We may therefore conclude that nitrogen-containing species near the center of the substrate originate from di-nitrogen in the feed gas that has reacted at

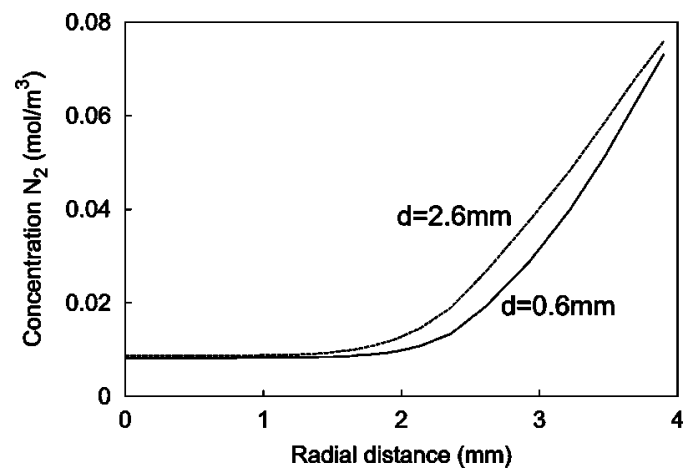

FIG. 7. Simulated radial concentration distribution of di-nitrogen directly above the substrate surface, for a di-nitrogen feed concentration of 1000 ppm and two different flame-tip-to-substrate distances: $d=0.6 \mathrm{~mm}$ and $d$ $=2.6 \mathrm{~mm}$. 
the flame front. This is in agreement with findings by Stolk and co-workers, ${ }^{58}$ who report that deposition in the central region is dominated by nitrogen in the feed.

Going back to Fig. 4, we see that HOCN in the outer flame region is mainly produced near the nozzle. Further downstream along the outer flame streamline, HOCN is decomposed and diluted by diffusion. This results in decreasing HOCN concentrations. Other nitrogen-containing species in the outer flame region are also produced mainly near the nozzle, but the rate at which their concentration decreases further downstream varies from species to species, as can be seen by comparing Figs. 4(a) to 6(a). The degree to which the high concentration outer flame zone extends to the substrate surface determines the species concentration distribution directly above that surface. When the concentration in the outer flame zone decreases rapidly [as for e.g., HOCN in Fig. 4(a)], most of the reaction product formed in the outer flame region does not reach the substrate surface. As a result, the HOCN which is present close to the surface center is predominantly originating from di-nitrogen in the feed gas, which is converted at the flame front. Consequently, the radial near-surface HOCN concentration profile in Fig. 4(b) has a clear maximum in the center. This maximum decreases by a factor 10 when di-nitrogen is omitted from the feed gas, again indicating that HOCN near the surface is predominantly due to di-nitrogen in the feed. Very similar concentration profiles as shown for HOCN in Fig. 4 are found for $\mathrm{HNCO}$ and $\mathrm{HCNO}$, which also exhibit a maximum nearsurface concentration at $r=0$.

The other extreme is found for NO, see Fig. 5(a). For this species, as well as for $\mathrm{HNO}, \mathrm{N}_{2} \mathrm{O}, \mathrm{NO}_{2}, \mathrm{~N}_{2} \mathrm{H}$, and $\mathrm{N}_{2}$, the outer flame region concentration does not decrease along the outer flame streamline, and dominates the concentration distribution near the substrate surface for larger radii. Consequently, their near-surface concentrations increase monotonously with increasing radius [see Fig. 5(b)]. Therefore, these species are unlikely as well to be responsible for the high growth rate annulus observed experimentally.

In between these two extremes are several species for which the near-surface concentration profile equally depends on the production rate in the flame front and in the outer flame region. For example, Fig. 6 shows iso-concentration lines and the radial near-surface concentration profile for $\mathrm{CN}$. This species exhibits a near-surface concentration maximum at $r \simeq 1.5 \mathrm{~mm}$. This is in qualitative agreement with experimental observations in Refs. 18 and 58, in which very similar profiles are found with a maximum around $r$ $\simeq 2.5-3.5 \mathrm{~mm}$. A similar behavior is found for $\mathrm{NH}, \mathrm{NH}_{2}$, $\mathrm{NH}_{3}, \mathrm{HCN}, \mathrm{H}_{2} \mathrm{CN}$, and NCO. The near-surface concentration profiles of all these species exhibits a local maximum at a radius around $r=1.5-2.5 \mathrm{~mm}$.

In conclusion, if we assume that the experimentally observed annular ring of low quality diamond is caused by a nitrogen-containing species that is present in relatively high concentrations in that same annular region, this eliminates the species that exhibit a maximum concentration near the center (HOCN, HNCO, and $\mathrm{HCNO}$ ), as well as those species for which the concentration increases monotonously with radius ( $\mathrm{NO}, \mathrm{HNO}, \mathrm{N}_{2} \mathrm{O}, \mathrm{NO}_{2}, \mathrm{~N}_{2} \mathrm{H}$, and $\mathrm{N}_{2}$ ). This leaves $\mathrm{NH}$,
$\mathrm{NH}_{2}, \mathrm{NH}_{3}, \mathrm{CN}, \mathrm{HCN}, \mathrm{H}_{2} \mathrm{CN}$, and $\mathrm{NCO}$ as possible candidates.

\section{CONCLUSIONS}

Detailed simulations were carried out of the (1D and 2D) hydrodynamics, combustion chemistry, and nitrogen chemistry in an oxyacetylene reactor for diamond deposition. Thus, the main mechanisms for di-nitrogen decomposition and the influence of nitrogen on the combustion process were identified, and concentration distributions of nitrogen-containing species in the gas phase and near the growth surface were computed.

The simulation results were used to evaluate five previously proposed hypotheses for the influence of di-nitrogen on diamond growth in oxyacetylene diamond combustion CVD: (i) Depletion of gaseous diamond precursors, owing to formation of CN. (ii) Decrease of the atomic hydrogen concentration in the gas-phase. (iii) Formation of $\mathrm{CN}$ in the gas phase, leading to etching through abstraction of hydrogen from the surface. (iv) The presence of nitrogen atoms in the diamond lattice, enhancing diamond growth. (v) Selective adsorption of nitrogen-containing species, selectively increasing growth in the (100) direction.

The first two hypotheses assume a significant influence of added nitrogen on the hydrocarbon combustion process. Our simulations, however, show that, due to its low conversion, the addition of di-nitrogen to the feed has hardly any effect on the concentration of the non-nitrogen-containing species. The same holds for di-nitrogen diffusing into the flame from the ambient air. Although the concentration of nitrogen-containing radicals in the outer flame zone is much larger than at the flame front, these species do not diffuse all the way into the flame to reach the central region of the diamond film. As a result, the concentrations of nitrogencontaining species are very small and their influence on the hydrocarbon combustion process is negligible. The third hypothesis, an etching role of $\mathrm{CN}$ on the surface comparable to that of $\mathrm{H}$, could not be supported either, since the predicted maximum $\mathrm{CN}$ concentration in the flame is orders of magnitude smaller than the maximum concentration of, e.g., atomic hydrogen. In fact, since the maximum concentrations of all nitrogen-containing gas-phase species are very low, it is unlikely that any nitrogen-containing species influences diamond growth via a direct etching effect.

This leaves hypotheses (iv) and (v) as the most likely explanations for the measured growth-rate-increasing effect of nitrogen in the central region, viz. nitrogen is either included in the diamond lattice, or nitrogen species are adsorbed on the diamond lattice. The question of a possible gas-phase candidate responsible for this effect is addressed here based on two-dimensional reactor simulations. For each nitrogen-containing gas-phase species, the radial profile at the diamond surface was evaluated. Based on this, the list of possible candidates affecting diamond growth was shortened, leaving $\mathrm{NH}, \mathrm{NH}_{2}, \mathrm{NH}_{3}, \mathrm{CN}, \mathrm{HCN}, \mathrm{H}_{2} \mathrm{CN}$, and $\mathrm{NCO}$ as possible candidates. 


\section{Acknowledgements}

The authors would like to thank Professor J. J. Ter Meulen, Dr. R. J. H. Klein-Douwel, and Dr. R. L. Stolk of the Catholic University of Nijmegen, The Netherlands, for many valuable discussions on this work, and Dr. R. L. Stolk for critically proofreading the manuscript.

${ }^{1}$ K. E. Spear and J. P. Dismukes, Synthetic Diamond, Emerging CVD Science and Technology (Wiley, New York, 1994).

${ }^{2}$ C. Johnston, Chim. Oggi 14, 17 (1996).

${ }^{3}$ J. J. Schermer, W. J. P. van Enckevort, and L. J. Giling, Diamond Relat. Mater. 3, 408 (1994).

${ }^{4}$ B. Atakan and K. Kohse-Höinghaus, Z. Metallkd. 92, 1139 (2001).

${ }^{5}$ B. Atakan and K. Kohse-Höinghaus, New Diamond Front. Carbon Technol. 11, 159 (2001).

${ }^{6}$ K. J. Kuijlaars, C. R. Kleijn, and H. E. A. van den Akker, Solid-State Electron. 42, A43 (1998).

${ }^{7}$ C. R. Kleijn, M. Okkerse, and H. E. A. VandenAkker, in Computational Technologies for Fluid/Thermal/Structural Chemical Systems with Industrial Applications, edited by V. V. Kudriavtsev and C. R. Kleijn (ASME, New York, 1999), Vol. I, pp. 219-226.

${ }^{8}$ C. R. Kleijn, Thin Solid Films 365, 294 (2000).

${ }^{9}$ M. Masi and S. Kommu, Semicond. Semimetals 72, 185 (2001).

${ }^{10}$ M. Masi, J. Phys. IV 11, 117 (2001).

${ }^{11}$ F. Di Muzio, C. Cavallotti, G. Cocchi, M. Gerli, M. Masi, and S. Carrà, in Computational Technologies for Fluid/Thermal/Structural/Chemical Systems with Industrial Applications, Volume II, edited by C. R. Kleijn and S. Kawano (ASME, New York, 1999), pp. 51-60.

${ }^{12}$ E. Meeks, R. J. Kee, D. S. Dandy, and M. E. Coltrin, Combust. Flame 92, 144 (1993)

${ }^{13}$ M. Okkerse, M. H. J. M. de Croon, C. R. Kleijn, G. B. Marin, and H. E. A. van den Akker, J. Appl. Phys. 84, 6387 (1998).

${ }^{14}$ M. Okkerse, C. R. Kleijn, H. E. A. van den Akker, M. H. J. M. de Croon, and G. B. Marin, J. Appl. Phys. 88, 4417 (2000).

${ }^{15}$ J. J. Schermer, J. E. M. Hogenkamp, G. C. J. Otter, G. Janssen, W. J. P. van Enckevort, and L. J. Giling, Diamond Relat. Mater. 2, 1149 (1993).

${ }^{16}$ R. J. H. Klein-Douwel, J. J. L. Spaanjaars, and J. J. ter Meulen, J. Appl. Phys. 78, 2086 (1995).

${ }^{17}$ R. J. H. Klein-Douwel and J. J. ter Meulen, J. Appl. Phys. 83, 4734 (1998).

${ }^{18}$ R. J. H. Klein-Douwel, J. J. Schermer, and J. J. ter Meulen, Diamond Relat. Mater. 7, 1118 (1998).

${ }^{19}$ A. Bergmaier, G. Dollinger, T. Faestermann, C. M. Frey, M. Ferguson, H. Güttler, G. Schultz, and H. Willerscheid, Diamond Relat. Mater. 5, 995 (1996).

${ }^{20}$ R. Locher, C. Wild, N. Herres, D. Behr, and P. Koidl, Appl. Phys. Lett. 65, 34 (1994).

${ }^{21}$ S. Jin and T. D. Moustakas, Appl. Phys. Lett. 65, 403 (1994).

${ }^{22}$ T. Vandevelde, M. Nesladek, C. Quaeyhaegens, and L. Stals, Thin Solid Films 290-291, 143 (1996).

${ }^{23}$ T. Vandevelde, M. Nesladek, C Quaeyhaegens, and L. Stals, Thin Solid Films 308-309, 154 (1997).

${ }^{24}$ S. Bohr, R. Haubner, and B. Lux, Appl. Phys. Lett. 68, 1075 (1996).

${ }^{25}$ G. Z. Cao, J. J. Schermer, W. J. P. van Enckevort, W. A. L. M. Elst, and L. J. Giling, J. Appl. Phys. 79, 1357 (1996).

${ }^{26}$ R. S. Tsang, C. A. Rego, P. W. May, M. N. R. Ashfold, and K. N. Rosser, Diamond Relat. Mater. 6, 247 (1997).

${ }^{27}$ A. Afzal, C. A. Rego, W. Ahmed, and R. I. Cherry, Diamond Relat. Mater. 7, 1033 (1998)
${ }^{28}$ B. Atakan, M. Beuger, and K. Kohse-Höinghaus, Phys. Chem. Chem. Phys. 1, 705 (1999).

${ }^{29}$ J. J. Schermer and F. K. de Theije, Diamond Relat. Mater. 8, 2127 (1999).

${ }^{30}$ F. K. de Theije, J. J. Schermer, and W. J. P. van Enckevort, Diamond Relat. Mater. 9, 1439 (2000).

${ }^{31}$ R. L. Stolk, M. M. J. W. van Herpen, J. J. Schermer, and J. J. ter Meulen, P. Combust. Inst. 28, 1447 (2000).

${ }^{32}$ J. Mort, M. A. Machonkin, and K. Okumura, Appl. Phys. Lett. 59, 3148 (1991).

${ }^{33}$ R. Haubner, S. Bohr, and B. Lux, Diamond Relat. Mater. 8, 171 (1999).

${ }^{34}$ T-M. Hong, S-H. Chen, Y-S Chiou, and C-F. Chen, Thin Solid Films 270, 148 (1995).

${ }^{35}$ T-M. Hong, S-H. Chen, Y-S Chiou, and C-F. Chen, Appl. Phys. Lett. 67, 2149 (1995)

${ }^{36}$ H. Chatei, J. Bougdira, M. Rémy, P. Alnot, C. Bruch, and J. K. Krüger, Diamond Relat. Mater. 6, 107 (1997).

${ }^{37}$ H. Chatei, J. Bougdira, M. Rémy, P. Alnot, C. Bruch, and J. K. Krüger, Diamond Relat. Mater. 6, 505 (1997).

${ }^{38}$ A. Badzian and T. Badzian, Appl. Phys. Lett. 62, 3432 (1993).

${ }^{39}$ Th. Frauenheim, G. Jungnickel, P. K. Sitch, M. Kaukonen, F. Weich, J. Widany, and D. Porezag, Diamond Relat. Mater. 7, 348 (1998).

${ }^{40}$ R. B. Bird, W. E. Stewart, and E. N. Lightfood, Transport Phenomena (Wiley, New York, 1960).

${ }^{41}$ C. R. Kleijn, in Computational Modeling in Semiconductor Processing, edited by M. Meyyappan (Artech House, Boston, 1995), Chap. 4, pp. 97-229.

${ }^{42}$ J. O. Hirschfelder, C. F. Curtiss, and R. B. Bird, Molecular Theory of Gases and Liquids (Wiley, New York, 1967).

${ }^{43}$ R. J. Kee, F. M. Rupley, and J. A. Miller, Technical Report No. SAND878215B.UC-4, 1990: (can be obtained from: Reaction Design, Inc., 6440 Lusk Bvd., Suite D209, San Diego, CA 92121, or http:// www.ReactionDesign.com).

${ }^{44}$ R. J. Kee, G. Dixon-Lewis, J. Warnatz, M. E. Coltrin, and J. A. Miller, Technical Report No. SAND86-8246.UC-401, 1991 (can be obtained from: Reaction Design, Inc., 6440 Lusk Bvd., Suite D209, San Diego, CA 92121, or http://www.ReactionDesign.com).

${ }^{45}$ C. R. Wilke, Chem. Eng. Prog. 46, 95 (1950).

${ }^{46}$ J. Miller and C. Melius, Combust. Flame 91, 2139 (1992).

${ }^{47}$ S. Skokov, B. Weiner, and M. Frenklach, J. Phys. Chem. 98, 7073 (1994).

${ }^{48}$ S. Skokov, B. Weiner, and M. Frenklach, J. Phys. Chem. 99, 5616 (1995).

${ }^{49}$ S. Skokov, B. Weiner, M. Frenklach, Th. Frauenheim, and M. Sternberg, Phys. Rev. B 52, 5426 (1995)

${ }^{50}$ M. E. Coltrin, R. J. Kee, G. H. Evans, E. Meeks, F. M. Rupley, and J. F. Grcar, Technical Report No. SAND91-8003.UC-401, 1993 (can be obtained from: Reaction Design, Inc., 6440 Lusk Bvd., Suite D209, San Diego, CA 92121, or http://www.ReactionDesign.com).

${ }^{51}$ M. C. Drake and R. J. Blint, Combust. Sci. Technol. 75, 261 (1991).

${ }^{52}$ P. Kilpinen, P. Glarborg, and M. Hupa, Ind. Eng. Chem. Res. 31, 1477 (1992).

${ }^{53}$ R. J. Kee, F. M. Rupley, and J. A. Miller, Technical Report No. SAND898009B, 1989.

${ }^{54}$ C. A. Wolden, C. E. Draper, Z. Sitar, and J. T. Prater, Diamond Relat. Mater. 7, 1178 (1998)

${ }^{55}$ R. J. H. Klein-Douwel, $\mathrm{PhD}$ thesis, Katholieke Universiteit Nijmegen, 1997.

${ }^{56}$ C. R. Kleijn and Ch. Werner, Modeling of Chemical Vapor Deposition of Tungsten Films (Birkhäuser, Basel, 1993).

${ }^{57}$ C. R. Kleijn, J. Electrochem. Soc. 138, 2190 (1991).

${ }^{58}$ R. L. Stolk, M. M. J. W. van Herpen, J. J. ter Meulen, and J. J. Schermer, J. Appl. Phys. 88, 3708 (2000). 